\title{
Laboratory Investigation of the 900-km Lapland Extreme Challenge
}

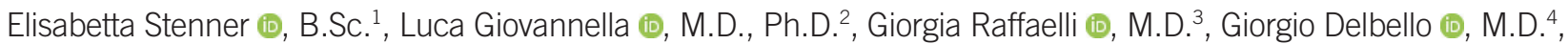 \\ Maurizio Ruscio $\mathbb{C}^{0}$, M.D. $^{1}$, and Roberto Verna $\mathbb{1 0}$, M.D., Ph.D. ${ }^{5,6}$ \\ ${ }^{1}$ SC Laboratorio Unico di ASUITs, Burlo, Gorizia e Monfalcone, Dipartimento di Medicina dei Servizi, Azienda Sanitaria Universitaria di Trieste, Trieste, Italy; \\ ${ }^{2}$ Centro Malattie Tiroidee, Clinica di Medicina Nucleare e Imaging Molecolare, Istituto di Imaging della Svizzera Italiana, Bellinzona, Switzerland; ${ }^{3} U .0 . C$. \\ Medicina Trasfusionale e Patologia Clinica, Repubblica di San Marino - Istituto per la Sicurezza Sociale, San Marino, Republic of San Marino; ${ }^{4}$ Dipartimento \\ di Scienze Mediche Chirurgiche e della Salute, Università degli Studi di Trieste, Trieste, Italy; ${ }^{5}$ World Association of Societies of Pathology and Laboratory \\ Medicine, Milan, Italy; ${ }^{6}$ Department of Experimental Medicine, Sapienza University of Rome, Rome, Italy
}

\section{Dear Editor,}

The Lapland Extreme Challenge (LEC) is a $900 \mathrm{~km}$ ultra-event through the Finnish Lapland wilderness. It was created in 2013; the time limit of the event is 30 days, but 2017 was the only year, in which this ultra-event had finishers. The athletes need to transport with them everything necessary to survive. As an outstanding stress model, it includes strenuous exercise, freezing temperatures, sleep restriction, and isolation/solitude, and all of them present simultaneously [1].

This study aimed to monitor biochemical parameters (BP) from the training (October 2016) through the restoring period (June 2017). However, owing to the high skill level required to perform the LEC, only one athlete (age: 51 years, sex: male, height: $177 \mathrm{~cm}$ ) was monitored. During the race, he travelled 30-40 km in 10-12 hours a day, dragging a sled of about 50 $\mathrm{kg}$, using skis for one half and snow boots for the other. He slept around five hrs a day, mostly in a tent. He ate mostly lyophilized food for a total of 3,800-4,200 kcal/day (about 25\% carbohydrate, $65 \%$ fat, and $10 \%$ protein) and drank about $2.5 \mathrm{~L}$ /day of liquefied snow with mineral salt added. The environmental temperatures ranged from $-15^{\circ} \mathrm{C}$ to $-36^{\circ} \mathrm{C}$. On the tenth day, after
$450 \mathrm{~km}$, he gave up due to frostbite (in his right thumb and part of the left foot, no permanent damage). BP were obtained at the following time points: 7:30 am, before the beginning of the training (T1: October 2016), each month before the LEC (T2: November 2016, T3: December 2016, T4: January 2017), immediately before and after the LEC (T5: February 2017, T6: March 2017), and each month after the LEC (T7: April 2017, T8: May 2017, T9: June 2017). Blood samples were centrifuged within two hours (in a hospital/on field); four aliquots of each blood sample drawn were frozen (two at $-80^{\circ} \mathrm{C}$ and two at $-20^{\circ} \mathrm{C}$ ) for five days, after which all parameters were measured. In this way, all blood samples were analyzed at the same time, thereby reducing pre-analytical variability. Inter-sample differences bigger than the critical reference change value (RCV) were considered significant [2]. RCV was calculated as follows:

$$
\mathrm{RCV}=2^{1 / 2} \times \mathrm{Z} \times\left(\mathrm{CVa}^{2}+\mathrm{CVw}^{2}\right)^{1 / 2}
$$

where $Z=1.96$ for $95 \%$ significance, $C V$ is the analytical variation and $\mathrm{CVW}$ is the coefficient of variation for intra-individual biological variation.

This study was performed according to the Code of Ethics of the World Medical Association (Declaration of Helsinki) for ex-
Received: April 21, 2019

Revision received: June 25, 2019

Accepted: August 7, 2019

Corresponding author: Roberto Verna, M.D., Ph.D. Department of Experimental Medicine, Sapienza University of Rome, Viale Regina Elena 324, Rome 00161, Italy Tel: +393711547775

E-mail: roberto.verna@uniroma1.it

\section{(c) (1) $(9$}

\section{(C) Korean Society for Laboratory Medicine}

This is an Open Access article distributed under the terms of the Creative Commons Attribution Non-Commercial License (http://creativecommons.org/licenses/by-nc/4.0) which permits unrestricted non-commercial use, distribution, and reproduction in any medium, provided the original work is properly cited. 
periments involving humans; the athlete provided informed consent.

The results are summarized in Table 1. Cortisol, bone alkaline phosphatase, and osteocalcin trends are shown in Fig. 1. The weight and body fat percentage of the athlete were $84 \mathrm{~kg}$ and $14.3 \%$ at $\mathrm{T} 1,70 \mathrm{~kg}$ and $11 \%$ at T6, and $82 \mathrm{~kg}$ and $15 \%$ at T9, respectively.
The increased creatine kinase values suggested muscle damage due to the high training workout. This was observed especially during the competition when creatine kinase, lactate dehydrogenase, and myoglobin significantly peaked [3]. However, frostbite to the right thumb and part of the left foot could have contributed to the increased biomarker values. Creatinine shows changes within the RCV for subjects undergoing regular aerobic

Table 1. Biochemical parameters during the four-month training period (T1-T5), immediately after the Lapland Extreme Challenge (T6), and a few months after the Lapland Extreme Challenge (T7-T9)

\begin{tabular}{|c|c|c|c|c|c|}
\hline Analyte & Reference range & RCV (\%) & $\begin{array}{c}\mathrm{T} 1-\mathrm{T} 5 \\
\text { mean } \pm \text { SD (CV\%) }\end{array}$ & T6 & $\begin{array}{c}\text { T7-T9 } \\
\text { mean } \pm \text { SD (CV\%) }\end{array}$ \\
\hline Creatine kinase $(\mu \mathrm{Kat} / \mathrm{L})^{*}$ & $0.42-3.31$ & 39 & $6.66 \pm 5.49(82)$ & 12.39 & $5.25 \pm 2.23(42)$ \\
\hline Lactate dehydrogenase ( $\mu \mathrm{Kat} / \mathrm{L})^{*}$ & $<4.17$ & 23 & $3.40 \pm 1.12(33)$ & 4.27 & $2.95 \pm 0.13(5)$ \\
\hline Myoglobin $(\mathrm{nmol} / \mathrm{L})^{\dagger}$ & $<4.00$ & 43 & $1.66 \pm 0.17(12)$ & 2.40 & $1.83 \pm 0.34(18)$ \\
\hline Sodium (mmol/L)* & $135-145$ & 5 & $140 \pm 1(0.8)$ & 140 & $140 \pm 1(0.7)$ \\
\hline Potassium (mmol/L)* & $3.50-5.10$ & 8 & $4.63 \pm 0.49(11)$ & 5.57 & $4.5 \pm 0.5(11)$ \\
\hline Phosphorus (mmol/L)* & $0.81-1.45$ & 15 & $1.16 \pm 0.07(6)$ & 1.16 & $1.13 \pm 0.01(0.3)$ \\
\hline Calcium (mmol/L)* & $2.12-2.62$ & 5 & $2.31 \pm 0.11(5)$ & 2.21 & $2.31 \pm 0.13(6)$ \\
\hline Magnesium (mmo//L)* & $0.73-1.05$ & 8 & $0.82 \pm 0.02(2)$ & 0.90 & $0.86 \pm 0.03(4)$ \\
\hline Enzymatic creatinine $(\mu \mathrm{mol} / \mathrm{L})^{*}$ & 44-115 & 12 & $86 \pm 2(3)$ & 103 & $91 \pm 4(5)$ \\
\hline Cystatin C (mg/L) & $0.20-0.62$ & NA & $0.25 \pm 0.02(7)$ & 0.25 & $0.27 \pm 0.03(10)$ \\
\hline Neutrophil gelatinase-associated lipocalin $(\mu \mathrm{g} / \mathrm{L})^{\ddagger}$ & $\leq 60$ & NA & $20 \pm 0(0)$ & 20 & $20 \pm 10(34)$ \\
\hline Bone alkaline phosphatase $(\mu \mathrm{g} / \mathrm{L})^{\dagger}$ & $3.70-21.00$ & 20 & $9.92 \pm 0.96(10)$ & 7.1 & $10.30 \pm 0.15(1.5)$ \\
\hline Carboxy-terminal collagen crosslinks $(\mathrm{ng} / \mathrm{L})^{\S}$ & $120-750$ & 30 & $530 \pm 60(11)$ & 390 & $470 \pm 30(6)$ \\
\hline 25-hydroxy-vitamin D (nmol/L)" & $75-125$ & NA & $82 \pm 5(6)$ & 78 & $67 \pm 12(20)$ \\
\hline Osteocalcin $(\mu \mathrm{g} / L)^{\|}$ & $4.60-65.40$ & 31 & $17.20 \pm 1.90(11)$ & 9.2 & $17.10 \pm 1.40(8)$ \\
\hline Parathyroid hormone $(\mathrm{ng} / \mathrm{L})^{\dagger}$ & $11-88$ & 55 & $36 \pm 10(29)$ & 32 & $51 \pm 22(42)$ \\
\hline Cortisol $(\mathrm{nmol} / \mathrm{L})^{\dagger}$ & $185-624$ & 31 & $417 \pm 77(18)$ & 178 & $452 \pm 97(21)$ \\
\hline
\end{tabular}

${ }^{*}$ Analytes were tested using the AU5800 analyzer (Beckman Coulter, Fullerton, CA, USA); ${ }^{\dagger}$ Analytes were tested using the UniCel DXI800 system (Beckman Coulter); ${ }^{\ddagger}$ Analytes were tested using the CKD Array II, Chemiluminescence Biochip Array Technology (Evidence Series; Randox Laboratories Ltd., Crumlin, UK); ${ }^{\S}$ Analyte was tested using the Alisei system (Omnia Diagnostic, Cranbury, NJ, USA); "Analytes were tested using the Liaison XL analyzer (Diasorin, Saluggia, TO, Italy).

Abbreviations: RCV, reference change value; NA, not available.
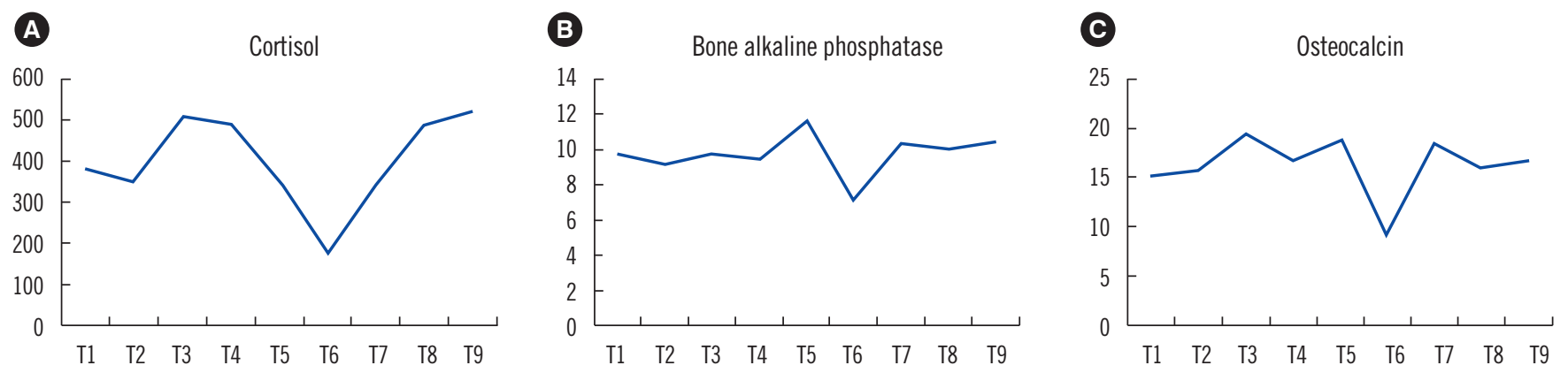

Fig. 1. Changes in biochemical parameters during the four-month training period (T1-T5), immediately after the Lapland Extreme Challenge (T6), and a few months after the Lapland Extreme Challenge (T7-T9): (A) Cortisol, (B) bone alkaline phosphatase, and (C) osteocalcin. 
training [4]. Moreover, cystatin- $C$ and neutrophil gelatinase-associated lipocalin remained basically unchanged, suggesting the absence of any exercise-associated renal impairment [5]. The significant increase in potassium observed after the LEC (T6) was at least in part due to the possible exercise-induced metabolic acidosis, which promotes extracellular accumulation of $\mathrm{K}+$ (controlled by KATP channels) [6]. Sodium, phosphorus, and magnesium values were basically unchanged, suggesting electrolyte homeostasis.

The decrease in bone formation biomarker values (bone alkaline phosphatase and osteocalcin) after the LEC (T6) indicated a temporary suppression of bone formation, partly due to the exercise associated with the severe energy deficit that leads to a notable reduction (-12.5\%) in total body weight after LEC [7].

Cortisol values remained within the reference range except after the LEC (T6), when they dropped significantly. This was in part unexpected considering that long duration exercise, sleep deprivation, and extreme conditions seem to increase the pituitary-adrenal cortex response [8]. However, another study regarding cortisol responses to extreme sports highlighted a significant drop during the performance, ending with values below the basal value [9]. A possible explanation could be that for these elite athletes, including the one we monitored, the extreme challenge is essential for their psychological well-being [10]. Consequently, it could be associated with less cortisol secretion, independently of the intense load and risk associated with severe environmental conditions.

In conclusion, apart from frostbite, this athlete seemed to respond physiologically to an extreme exercise load despite the transient decrease in bone formation biomarker values. It suggests that precaution should be taken in constant ultra-endurance training and frequent ultra-endurance competitions.

\section{Acknowledgements}

The authors thank Dr. Nicholas Carter for proofreading this article.

\section{Author Contributions}

All authors have accepted their responsibility for the entire content of this manuscript and approved submission.

\section{Conflicts of Interest}

None declared.

\section{Research Funding}

None declared.

\section{ORCID}

Elisabetta Stenner

https://orcid.org/0000-0001-9330-1117

Luca Giovannella https://orcid.org/0000-0003-0230-0974

Giorgia Raffaelli https://orcid.org/0000-0002-3430-0218

Giorgio Delbello https://orcid.org/0000-0001-5006-1272

Maurizio Ruscio https://orcid.org/0000-0003-3928-6408

Roberto Verna

\section{REFERENCES}

1. Lucas SJE, Helge JW, Schütz UHW, Goldman RF, Cotter JD. Moving in extreme environments: extreme loading; carriage versus distance. Extrem Physiol Med 2016;5:6.

2. Walz B and Fierz W. The concept of reference change values (RCV). Will it supersede reference intervals? Ther Umsch 2015;72:130-5.

3. Rawson ES, Clarkson PM, Tarnopolsky MA. Perspectives on exertional rhabdomyolysis. Sports Med 2017;47(S1):S33-49.

4. Nunes LA, Brenzikofer R, de Macedo DV. Reference change values of blood analytes from physically active subjects. Eur J Appl Physiol 2010; 110:191-8.

5. Hewing B, Schattke S, Spethmann S, Sanad W, Schroeckh S, Schimke I, et al. Cardiac and renal function in a large cohort of amateur marathon runners. Cardiovasc Ultrasound 2015;13:13.

6. Sumi D, Kojima C, Kasai N, Goto K. The effects of endurance exercise in hypoxia on acid-base balance and potassium kinetics: a randomized crossover design in male endurance athletes. Sports Med Open 2018; 4:45.

7. Zanker $\mathrm{CL}$ and Cooke CB. Energy balance, bone turnover, and skeletal health in physically active individuals. Med Sci Sports Exerc 2004;36: 1372-81.

8. Vaananen I, Vasankari T, Mäntysaari M, Vihko V. Hormonal responses to $100 \mathrm{~km}$ cross-country skiing during 2 days. J Sports Med Phys Fitness 2004;44:309-14.

9. Stenner E, Gianoli E, Piccinini C, Biasioli B, Bussani A, Delbello G. Hormonal responses to a long duration exploration in a cave of $700 \mathrm{~m}$ depth. Eur J Appl Physiol 2007;100:71-8.

10. Clough P, Houge Mackenzie S, Mallabon L, Brymer E. Adventurous physical activity environments: a mainstream intervention for menta health. Sports Med 2016:46:963-8. 